\title{
Substrato à base de pequi (Caryocar coriaceum) na produção de mudas de tomate e pimentão
}

\author{
Tamires Coelho Matias Maciel ${ }^{1}$, Toshik Iarley da Silva², Francisca Dayanne de Oliveira \\ Alcantara ${ }^{1}$, Cláudia Araújo Marco', Ricardo Luiz Lange Ness ${ }^{1}$ \\ ${ }^{1}$ Universidade Federal do Cariri (UFCA), Campus Crato, Crato, Ceará, Brasil. E-mail: tamires.coelho.matias@gmail.com, \\ dayannealcantara14@gmail.com, claudia.marco@ufca.edu.br, ricardo.ness@ufca.edu.br \\ ${ }^{2}$ Universidade Federal da Paraíba (UFPB), Campus Areia, Areia, Paraíba, Brasil. E-mail: iarley.toshik@gmail.com
}

Recebido: 14/03/2017; Aceito: 18/04/2017.

\section{RESUMO}

Em meio à riqueza vegetal da Chapada do Araripe ocorre o extrativismo do pequi (Caryocar coriaceum) como importante atividade econômica e social das principais cidades do Cariri Cearense. Assim, o presente trabalho teve como objetivo a utilização dos resíduos dessa atividade como substrato na produção de mudas de tomate (Solanum licopersicum) e pimentão (Capsicum аппиит). O experimento foi conduzido na área experimental do Centro de Ciências Agrárias e Biodiversidade da Universidade Federal do Cariri. O delineamento experimental foi inteiramente casualizado com cinco tratamentos e seis repetições, com dezesseis células (plantas) para cada repetição. Os dados obtidos foram submetidos à análise de variância e as médias comparadas pelo teste de Tukey a 5\% de probabilidade. Nas mudas foram avaliadas a porcentagem de emergência, o índice de velocidade de emergência, o tempo médio de emergência, a facilidade de retirada da plântula da célula, a agregação do substrato às raízes, a necrose da radícula, o comprimento da raiz e a biomassa seca foliar e radicular. $\mathrm{O}$ uso dos resíduos para produção de composto obteve resultados satisfatório quando utilizado com solo em proporções iguais, produzindo mudas de pimentão e tomate de qualidade nas condições da região do Cariri cearense.

Palavras-chave: resíduos agrícolas, adubação, Solanum licopersicum, Capsicum annuит.

\section{Substrate consisting of pequi (Caryocar coriaceum) on production of tomato and sweet pepper seedlings}

\begin{abstract}
Among the plant richness of the Araripe Chapada occurs the extractivism of pequi (Caryocar coriaceum) as important activity that reaches the economy and social activity of the main cities of Cariri Cearense. Thus, the present work has as objective the use of waste of this activity as substrate in tomato (Solanum licopersicum) and sweet pepper (Capsicum апnиит) seedling production. The experiment was conducted in the Center of Agrarian Sciences and Biodiversity at the Federal University of Cariri. The experimental design was completely randomized with five treatments and six repetitions, with sixteen cells (plants) to each repetition. The data were submitted to variance analysis and the mean compared by Tukey test at $5 \%$ of probability. In the seedlings were evaluated the percentage of emergence, emergence speed index, emergence mean time, the ease of removal of the seedlings from the cell, substrate aggregation to the roots, radicle necrosis, root length and leaf and root dry biomass. The use of pequi residues to produce substrate obtained satisfactory results when it's utilized with soil in equal proportions, producing tomato and sweet pepper with quality in the regional conditions of Cariri Cearence.
\end{abstract}

Key words: agricultural waste, fertilizing, Solanum licopersicum, Capsicum annuит. 


\section{Introdução}

O pimentão (Capsicum annuum L.) pertencente à família Solanaceae, é uma das dez hortaliças mais consumidas no Brasil (HENZ et al., 2007). O tomateiro (Solanum lycopersicum L.), também pertence à esta mesma família, sendo uma das olerícolas de maior importância econômica e também uma das mais difundidas no mundo, devido a sua grande aceitabilidade e consumo. A demanda por estas hortaliças foi reforçada pela busca de alimentos mais saudáveis, favorecendo também o crescimento da venda do produto fresco (CARVALHO; PAGLIUCA, 2007).

Uma das fases que mais influenciam na produção de hortaliças é a formação de mudas, visto que estas influenciam diretamente no desempenho e na produtividade da cultura a ser implantada (COSTA et al., 2011). O substrato para a produção de mudas deve fornecer qualidades químicas e físicas, propiciando macro e microporosidade, umidade, água e nutrientes (COSTA et al., 2013). Muitos substratos são descritos para a produção de mudas de tomateiro e pimentão (ARAÚJO NETO et al., 2009; CAMPANHARO et al., 2010; RODRIGUES et al., 2010). Dentre os substratos, destacam-se os oriundos da decomposição da matéria orgânica.

Dentre os processos de transformação de resíduos orgânicos se destacam a compostagem e a vermicompostagem, que diminuem o potencial contaminante dos resíduos ao converte-los em biofertilizantes e possibilitando a reciclagem dos nutrientes no solo (DOMÍNGUEZ et al., 2010). Depois de tratado, o resíduo é denominado de adubo orgânico ou fertilizante orgânico para uso agrícola. O uso desses fertilizantes é muito empregado na produção de hortaliças em várias regiões do mundo, favorecendo o desenvolvimento das plantas e contribuindo com a sustentabilidade ambiental pela diminuição do uso de adubação química.

A Região do Cariri, localizada no sul do Estado do Ceará, tem se destacado pelo grande avanço na exploração das hortaliças cuja característica principal é o emprego da agricultura familiar onde pequenas propriedades tentam empregar técnicas agroecológicas. Todas as cidades da região produzem de forma subsistente e dentre as hortaliças mais produzidas nessas cidades estão o tomate e o pimentão, ficando também entre as mais consumidas pela população local. Nesta mesma região há uma forte aptidão para o extrativismo do pequi (Caryocar coriaceum Wittm.), principalmente para a comercialização "in natura" e também do óleo extraído do fruto e das amêndoas.

O pequizeiro (Caryocar sp.), conhecido pelos nomes vulgares de pequi, pequá, amêndoa do espinho, grão de cavalo ou amêndoa do Brasil é uma espécie arbórea nativa do Cerrado brasileiro. Ocorre em quase todos os agroecossistemas do país e tem seus frutos muito apreciados e utilizados na culinária da Região CentroOeste, Norte e parte do Nordeste. Na parte mais setentrional do Nordeste Brasileiro é encontrada a espécie $C$. coriaceum Wittm., que assume importante papel socioeconômico na Chapada do Araripe e circunvizinhanças nos Estados do Ceará, Pernambuco e Piauí (OLIVEIRA et al., 2009).

No entanto, as cascas desse fruto são descartadas nos locais de coleta ou de sua comercialização, o que gera um grande acúmulo de material orgânico. Desta forma, buscou-se com esse trabalho testar o composto dos resíduos de casca de pequi (Caryocar coriaceum) como substrato na produção de mudas de tomate (Solanum lycopersicum) e pimentão (Capsicum annuum).

\section{Material e Métodos}

$\mathrm{O}$ experimento foi conduzido na área experimental do Centro de Ciências Agrárias e da Biodiversidade (CCAB) da Universidade Federal do Cariri (UFCA) localizado na cidade de Crato-CE com coordenadas geográficas: $7^{\circ} 14^{\prime}$ 03"de latitude sul e $39^{\circ} 24^{\prime} 34^{\prime \prime}$ de longitude oeste de Greenwich, onde a altitude média é de 426,9 m. A média anual de precipitação é de 1.090,9 $\mathrm{mm}$, com chuvas concentradas de janeiro a maio. As temperaturas médias ao longo do ano variam entre $24{ }^{\circ} \mathrm{C}$ e $26{ }^{\circ} \mathrm{C}$, com médias mínimas de $18{ }^{\circ} \mathrm{C}$ até médias máximas de $33{ }^{\circ} \mathrm{C}$ (IPECE, 2007). O solo da região é classificado como Latossolo Vermelho-Amarelo. Vale ressaltar que os Latossolos são muito intemperizados, com pequena reserva de nutrientes para as plantas e baixa CTC (capacidade de troca de cátions). Um fator limitante desse tipo de solo é a baixa fertilidade. Contudo, com aplicações adequadas de corretivos e fertilizantes, aliadas à época propícia de plantio, obtêmse melhores produções (SOUSA; LOBATO, 2004).

A amostragem composta de solo foi obtida da área experimental do $\mathrm{CCAB}$, de onde foi retirado o solo para compor os substratos da pesquisa. $\mathrm{O}$ solo foi analisado no Laboratório de Água, Solo e Tecidos Vegetais (LABAS) do Instituto Federal de Educação, Ciências e Tecnologia (IFCE) na cidade de Iguatu-CE (Tabela 1). No mesmo período do experimento foi realizada a análise química do composto à base de resíduos de pequi, produzido na área experimental do $\mathrm{CCAB}$, no Laboratório de Solo/Água da Universidade Federal do Ceará, na cidade de Fortaleza-CE (Tabela 2).

As coletas das cascas do pequi foram feitas através de visitas ao acampamento Barreiro Novo, Município de Jardim-CE. As cascas foram postas para secar naturalmente à sombra, no $\mathrm{CCAB}$ onde tiveram seu tamanho reduzido com o auxílio de uma máquina forrageira, tesouras e facões, pois quanto maiores as partículas incorporadas na pilha, mais demorado é o 
processo da compostagem. Posteriormente, esses resíduos foram levados para uma área previamente determinada para ser feita o processo de compostagem.

Tabela 1. Análise de fertilidade solo da área experimental do CCAB/UFCA.

\begin{tabular}{lcc}
\hline Nutrientes & Concentrações & \\
\hline $\mathrm{P}$ & 9,7 & $\mathrm{mg} \mathrm{dm}^{-3}$ \\
$\mathrm{~K}$ & 49,92 & \\
$\mathrm{Na}$ & 3,48 & \\
$\mathrm{Ca}$ & 9,0 & \\
$\mathrm{Mg}$ & 19,0 & $\mathrm{mmol}_{\mathrm{c}} \mathrm{dm}^{-3}$ \\
$\mathrm{Al}$ & 2,00 & \\
$\mathrm{H}+\mathrm{Al}$ & 13,20 & \\
$\mathrm{CTC}$ & 4,5 & $\mathrm{cmol}_{\mathrm{c}} \mathrm{dm}^{3}$ \\
\hline
\end{tabular}

Tabela 2. Concentração de nutrientes no composto orgânico a base de resíduos de pequi.

\begin{tabular}{lclc}
\hline Macronutriente & $\begin{array}{c}\text { Teor } \\
\left(\mathrm{g} \mathrm{kg}^{-1}\right)\end{array}$ & Micronutriente & $\begin{array}{c}\text { Teor } \\
\left(\mathrm{mg} \mathrm{kg}^{-1}\right)\end{array}$ \\
\hline $\mathrm{N}$ & 13,2 & $\mathrm{Fe}$ & 2083,9 \\
$\mathrm{P}$ & 2,4 & $\mathrm{Cu}$ & 24,2 \\
$\mathrm{P}_{2} \mathrm{O}_{5}$ & 5,4 & $\mathrm{Mn}$ & 221,9 \\
$\mathrm{~K}$ & 7,0 & $\mathrm{Zn}$ & 76,7 \\
$\mathrm{~K}_{2} \mathrm{O}$ & 8,5 & & \\
$\mathrm{Ca}$ & 10,3 & & \\
$\mathrm{Mg}$ & 6,1 & & \\
$\mathrm{~S}$ & 0,4 & & \\
$\mathrm{Na}$ & 2,0 & & \\
\hline
\end{tabular}

Para enriquecimento do composto e a fim de manter uma equilibrada relação $\mathrm{C} / \mathrm{N}$ utilizou-se, na mistura, palhas oriundas de folhas e hastes de plantas infestantes presentes na área experimental além de esterco bovino, em proporções iguais. As etapas da produção do composto orgânico foram realizadas em leiras montadas em formato cônico, dando-se cuidado especial à umidade e temperatura do composto na leira para que os microrganismos pudessem fazer a degradação desejada para o composto orgânico final. Para isso executou-se regas periódicas, tomando cuidado, para evitar o excesso de água que é prejudicial. A constatação prática da temperatura desejável foi realizada mediante apalpamento, com as costas das mãos, em uma barra de ferro que se deixou inserida no material empilhado, a uma profundidade mínima de $50 \mathrm{~cm}$. O revolvimento da leira foi feito a cada 15 dias de acordo com a necessidade, sendo estabelecido o monitoramento da temperatura e umidade a cada dois dias. A maturação das mesmas ocorreu com 104 dias após a sua formação. Depois desse período o composto formado foi peneirado e reservado para ser utilizado nas etapas subsequentes.

$\mathrm{O}$ delineamento experimental utilizado para os testes foi o inteiramente casualizado com cinco tratamentos e seis repetições de 16 plantas por parcela. O estudo foi conduzido em dois ensaios, um para tomate e o outro para o pimentão.

Os tratamentos consistiram em substratos utilizados nas seguintes proporções indicada na Tabela 3 .

Sementes de pimentão e tomate foram semeadas nas diferentes combinações de substrato, em bandejas de polipropileno expandido de 128 células, na profundidade de $1,0 \mathrm{~cm}$, colocando uma semente em cada célula da bandeja. As mesmas foram submetidas à irrigação manual com a utilização de regadores de crivos finos de modo a manter a umidade adequada logo após a semeadura, com duas aplicações diárias, quando necessário. A contagem das plantas emergidas ocorreu diariamente até o $16^{\circ}$ dia após a semeadura, quando houve a estabilização da emergência e foi considerada como emergida sementes que deram origem a plântulas normais, ou seja, com todas as suas estruturas essenciais bem desenvolvidas, completas, proporcionais e sadias. Tais registros serviram para as análises de porcentagem de emergência (PE), índice de velocidade de emergência (IVE) e tempo médio de emergência (TME).

A porcentagem de emergência (PE) foi representada pela porcentagem de plântulas emergidas; o índice de velocidade de emergência (IVE) foi mensurado pelas contagens diárias das plântulas emergidas durante os 16 dias e pela realização dos cálculos conforme a metodologia recomendada por Maguire (1962) e o tempo médio de emergência (TME) foi calculado pela fórmula citada por Silva e Nakagawa (1995).

Ao final do experimento (30 dias após a semeadura) realizou-se a avaliação de facilidade de retirada da plântula da célula (FR), agregação do substrato às raízes (AS) e necrose da radícula (N). Foi utilizado uma escala de um a três para caracterização da facilidade de retirada da plântula da célula (FR), agregação do substrato às raízes (AS), em que um representa a máxima dificuldade de retirada das plântulas ou esboroamento máximo dos torrões que compõem a célula, dois representa dificuldade intermediária para a retirada da plântula ou esboroamento mediano e três denota a máxima facilidade na retirada e apresenta o torrão da célula íntegro (CORREIA et al., 2003).

Tabela 3. Descrição dos materiais utilizados para produção dos tratamentos.

\begin{tabular}{clc}
\hline Tratamentos & \multicolumn{1}{c}{ Materiais Utilizados } & Proporção $^{-1}$ \\
\hline 1 & Solo $(\mathrm{S})^{1}$ & 1 \\
2 & Solo (S) e Composto (C) & $3: 1$ \\
3 & Solo (S) e Composto (C) & $3: 2$ \\
4 & Solo (S) e Composto (C) & $3: 3$ \\
5 & Composto (C) & 1
\end{tabular}

1: Horizonte A coletado de 0-65 $\mathrm{cm}$ de profundidade em solo Latossolo Vermelho amarelo, no município de Crato, CE. ${ }^{2}$ : Composto (proporções iguais de casca de pequi, palhas oriundas de folhas e hastes de plantas infestantes e esterco bovino). 
Para a avaliação de necrose na radícula $(\mathrm{N})$, as raízes foram lavadas em água corrente para a eliminação das partículas de solo, e deixadas sobre papel toalha para a retirada do excesso de água. Quando seca foi observado se havia mudança na coloração da raiz.

Para cada tratamento avaliou-se comprimento da raiz $(\mathrm{cm})$ e a biomassa seca foliar e radicular $(\mathrm{g})$ obtidas através da pesagem total das folhas e raízes secas. Nesta determinação as plantas foram pesadas e colocadas em sacos de papel, em seguida acomodadas por $48 \mathrm{~h}$ em estufa com circulação forçada de ar a $70{ }^{\circ} \mathrm{C}$.

Os dados obtidos foram submetidos à análise de variância e as médias comparadas pelo teste de Tukey a $5 \%$ de probabilidade utilizando o programa estatístico SISVAR/UFLA (FERREIRA, 2011).

\section{Resultados e Discussão}

Com base na amostra de solo, foi observado que o fósforo (P) e o potássio (K) apresentaram teores de 9,7 $\mathrm{mg} \mathrm{dm}{ }^{-3}$ e $50,05 \mathrm{mg} \mathrm{dm}^{-3}$, respectivamente (Tabela 1). $\mathrm{O}$ teor de $\mathrm{P}$ foi considerado baixo de acordo com Tedesco et al. (2004), algo indesejado já que seu fornecimento em dose adequada favorece o desenvolvimento do sistema radicular aumentando a absorção de água e de nutrientes; aumenta o vigor das plantas oriundas de semeadura direta; favorece a floração e a frutificação e aumenta a qualidade e o rendimento dos produtos colhidos (FILGUEIRA, 2008).

O K apresentou-se alto, segundo Tedesco et al. (2004), pois esse elemento é um dos nutrientes requeridos em maiores quantidades pelas culturas. Entretanto, diferentemente do nitrogênio, que pode ser disponibilizado por processos de fixação biológica, não existem fontes renováveis de potássio, de modo que sua disponibilidade às plantas depende essencialmente das reservas do solo e da aplicação de fertilizantes (CURI et al., 2005).

As faixas de interpretação dos teores de potássio no solo variam conforme a capacidade de troca de cátions (CTC) (SCHERER, 1998). Nesta análise o CTC mostrou-se baixo, algo indesejado, pois quanto maior a CTC do solo maior o número de cátions que o solo pode reter. Portanto, a CTC é uma característica físicoquímica fundamental ao manejo adequado da fertilidade do solo. Solos com CTC menor que $5 \mathrm{cmol}_{\mathrm{c}} \mathrm{dm}^{3}$, como é o caso do solo estudado (Tabela 1), apresentam baixa percentagem de argila e/ou baixo teor de matéria orgânica, apresentando assim menor capacidade de retenção de nutrientes e de umidade (LOPES; GUILHERME, 1992).

Através da análise da fertilidade do composto orgânico à base de resíduos de pequi verificou-se que seu uso é viável na elaboração de substrato para produção de mudas de hortaliças. A composição química do composto (Tabela 2), destes fertilizantes apresentam os principais macronutrientes ( $\mathrm{N}, \mathrm{P}$ e $\mathrm{K}$ ) requeridos no desenvolvimento dos vegetais (FILGUEIRA, 2008).

$\mathrm{O}$ nitrogênio $(\mathrm{N})$ foi o elemento que mais se destacou entre os macronutrientes apresentando 13,2 g $\mathrm{kg}^{-1}$ de composto, seguido do cálcio (Ca) com 10,3 $\mathrm{g} \mathrm{kg}^{-}$ 1. Em relação aos micronutrientes, o manganês $(\mathrm{Mn})$ e o ferro $(\mathrm{Fe})$ foram os que estavam presentes em maiores concentrações no composto produzido.

O composto orgânico apresentou características químicas satisfatórias para uso na agricultura, com valores de 13,2 $\mathrm{g} \mathrm{kg}^{-1}$ de $\mathrm{N} ; 5,4 \mathrm{~g} \mathrm{~kg}^{-1}$ de $\mathrm{P}_{2} \mathrm{O}_{5}$ e $8,5 \mathrm{~g}$ $\mathrm{kg}^{-1}$ de $\mathrm{K}_{2} \mathrm{O}$. Cada tonelada de composto orgânico apresenta, em média, 27,1 kg de $\mathrm{N}_{2} \mathrm{O}_{5} \mathrm{~K}_{2} \mathrm{O}, 10,3 \mathrm{~kg}$ de $\mathrm{Ca}, 6,1 \mathrm{~kg}$ de $\mathrm{Mg}$ e $0,4 \mathrm{~kg}$ de $\mathrm{S}$, além dos micronutrientes. Segundo Ribeiro et al., (1999) a fórmula de adubo químico usado para solos com baixa disponibilidade de nutrientes é a $150 \mathrm{~kg} / \mathrm{ha}$ de $\mathrm{N}, 400$ $\mathrm{kg} / \mathrm{ha}$ de $\mathrm{P}_{2} \mathrm{O}_{5}, 120 \mathrm{~kg} / \mathrm{ha}$ de $\mathrm{K}_{2} \mathrm{O}$, ou seja, $670 \mathrm{~kg}$ de NPK/tonelada de adubo químico, para um espaçamento de $30 \times 30 \mathrm{~cm}$ em cova esses valores seriam 1,34g de $\mathrm{N}$, $3,6 \mathrm{~g}$ de $\mathrm{P}_{2} \mathrm{O}_{5}$ e $1,07 \mathrm{~g}$ de $\mathrm{K}_{2} \mathrm{O}$, ou 6,01g de NPK/kg, esta mesma quantidade de $\mathrm{N}, \mathrm{P}_{2} \mathrm{O}_{5}$ e $\mathrm{K}_{2} \mathrm{O}$ é encontrada respectivamente em 100, 700 e $200 \mathrm{~g}$ do composto orgânico analisado.

Para a cultura do tomate houve uma grande variação com relação ao melhor tratamento onde o tratamento 4 (três partes de solo para três partes de composto) (Tabela 4) apresentou os melhores resultados para a maioria das características avaliadas, indicando a necessidade de o composto ser utilizado em mistura, podendo ser utilizado o solo, proporcionando assim melhor custo benefício para o produtor (PEREIRA et al., 2008). Tal resultado foi observado por Costa et al. (2013), aos quais avaliaram alguns substratos para a produção de mudas de tomate e pepino.

Observando as variáveis analisadas na Tabela 4 verificou-se que para comprimento das raízes (CR), massa seca da parte aérea (MSPA), massa seca da raiz (MSR), índice de velocidade de emergência (IVE) e porcentagem de emergência (PE) para a cultura do tomate não houve diferença estatística entre os substratos utilizados.

Rodrigues et al. (2010), ao estudarem a produção de tomateiro em diferentes substratos, ressaltam que o aumento da concentração de composto orgânico não possibilitou o aumento no crescimento das plântulas. Diniz et al. (2006) observaram que a adição de vermiculita em até $25 \%$ favoreceu o acúmulo de matéria seca da parte aérea de plântulas de tomate, sendo também observado o mesmo comportamento para a variável MSR. 
Tabela 4. Características agronômicas comprimento de raiz (CR), porcentagem de emergência (PE), tempo médio de emergência (TME), índice de velocidade de emergência (IVE), massa seca da parte aérea (MSPA), massa seca da raiz (MSR) avaliadas na produção de mudas de tomate com os diferentes substratos.

\begin{tabular}{lcccccc}
\hline \multirow{2}{*}{ Tratamentos } & \multicolumn{9}{c}{ Médias } & MSPA* & MSR* \\
\cline { 2 - 7 } & CR & PE & TME & IVE & & $(\mathrm{g})$ \\
\cline { 2 - 7 } & $5,22 \mathrm{a}$ & $76,66 \mathrm{a}$ & $3,67 \mathrm{ab}$ & $0,31 \mathrm{a}$ & $0,46 \mathrm{a}$ & $0,34 \mathrm{a}$ \\
\hline 1 - Solo & $5,42 \mathrm{a}$ & $71,66 \mathrm{a}$ & $3,93 \mathrm{a}$ & $0,29 \mathrm{a}$ & $0,40 \mathrm{a}$ & $0,30 \mathrm{a}$ \\
- (3) solo + (1) composto & $5,02 \mathrm{a}$ & $75,00 \mathrm{a}$ & $3,53 \mathrm{ab}$ & $0,29 \mathrm{a}$ & $0,41 \mathrm{a}$ & $0,36 \mathrm{a}$ \\
3 - (3) solo + (2) composto & $5,27 \mathrm{a}$ & $77,50 \mathrm{a}$ & $2,10 \mathrm{~b}$ & $0,34 \mathrm{a}$ & $0,41 \mathrm{a}$ & $0,34 \mathrm{a}$ \\
4 - Solo + composto & $4,87 \mathrm{a}$ & $72,50 \mathrm{a}$ & $3,52 \mathrm{ab}$ & $0,29 \mathrm{a}$ & $0,44 \mathrm{a}$ & $0,32 \mathrm{a}$ \\
5 - Composto & 9,02 & 7,89 & 28,24 & 12,32 & 19,95 & 21,91 \\
\hline CV (\%) & &
\end{tabular}

Médias seguidas de mesma letra, na coluna, não diferem entre si pelo teste de Tukey a 5\% de probabilidade. *Médias de dados transformados pela razão de $(\mathrm{x})^{\wedge} 0,5$.

Para CR a menor média $(4,87 \mathrm{~cm})$ obtida foi para o tratamento 5 (apenas composto) onde também pode-se observar que nos tratamentos com maiores quantidades de composto a base de pequi as raízes obtiveram médias com menores valores para a variável em discussão demostrando que o composto consegue reter umidade em níveis satisfatórios fazendo com que as raízes cresçam menos, pois não precisam procurar umidade. Marfá e Guri (1999) relataram que os sistemas de cultivo em substratos, limitam o crescimento das raízes a um volume menor, tais condições são determinadas pela disponibilidade de água e nutrientes, nível de salinidade e aeração no substrato. $\mathrm{O}$ aumento de matéria orgânica em substratos contribui para a melhoria da capacidade de armazenamento de água no mesmo (BORCHARTT et al., 2011).

A falta de matéria orgânica no solo pode ocasionar um déficit hídrico devido à baixa retenção de água, fazendo com que se torne necessário que a planta busque alternativas para se adaptar ao meio. De acordo com Santana et al. (2012), o material orgânico no solo resulta em muitos benefícios, tais como melhoria nas propriedades biológicas, físicas e químicas do solo, aumentando dessa forma o fornecimento de nutrientes às plantas.

Para massa seca da parte aérea (MSPA) não houve diferença estatística, ficando o tratamento 1 (solo) com maior média, seguido do tratamento 5 (apenas composto). Tal resultado contradiz com os encontrados por Santos et al. (2015), onde destacam que o aumento da concentração de composto orgânico promoveu maior elevação na MSPA de plântulas de tomate.

Conforme dados da Tabela 4, não houve diferença estatística para a variável massa seca da raiz (MSR), porém, o tratamento 3 (três partes de solo para duas de composto) promoveu a maior média. Segundo Filgueira (2008), um bom enraizamento e o reinício do desenvolvimento da planta após o choque do processo de transplante são favorecidos por tecidos ricos em massa seca. Costa et al. (2007), estudando o desenvolvimento de tomate em substratos comerciais e alternativos, destacam melhor desempenho dos substratos comerciais em razão de suas melhores características de retenção de água e aeração.

Com relação à variável MSR a pesquisa mostrou que quantidades superiores de solo com textura arenosa misturada com o composto de resíduos de pequi podem levar a raízes maiores, isso pode ser justificado pela textura do solo a qual facilita o desenvolvimento das raízes com a disponibilidade de nutrientes que o composto oferece. Costa et al. (2013), ressaltam que os resultados obtidos com o substrato à base de composto orgânico foram superiores aos com Plantmax ${ }^{\circledR}$ HT para a variável MSR em plântulas de tomate.

$\mathrm{O}$ índice de velocidade de emergência contado em dias obteve melhor média para o tratamento 5 revelando que o composto proporciona condições satisfatórias para emergência da semente; ao avaliarmos a porcentagem de emergência percebemos que o tratamento 4 obteve média mais satisfatória, mostrando que para manutenção das mudas quantidades iguais de composto e solo atendem melhor a exigência da cultura no período de estabelecimento de plântulas. Para a variável tempo médio de emergência, nota-se que houve diferença estatística, onde o tratamento 4 foi o que demostrou menor tempo para a emergência das plântulas. Campanharo et al. (2006), ao avaliarem o efeito de diferentes substratos em mudas de tomateiro destacam que o substrato constituído de uma mistura de pó de coco e composto orgânico mostrou os melhores resultados para o IVE.

No pimentão não houve diferença estatística para as características agronômicas CR, MSPA, MSR e TME. Essas mesmas variáveis apresentaram os melhores valores quando se utilizou o tratamento 4 (três partes de solo para três partes de composto), ficando o comprimento de raiz com $7,21 \mathrm{~cm}$, massa fresca e seda da parte aérea com $1,69 \mathrm{~g}$ e $0,49 \mathrm{~g}$, massa seca da raiz com 0,96 e $0,37 \mathrm{~g}$, respectivamente, e tempo médio de emergência de 4,50 dias (Tabela 5). 
Tabela 5. Características agronômicas comprimento de raiz (CR), porcentagem de emergência (PE), tempo médio de emergência (TME), índice de velocidade de emergência (IVE), massa seca da parte aérea (MSPA), massa seca das raízes (MSR) avaliadas na produção de mudas de pimentão com os diferentes substratos.

\begin{tabular}{|c|c|c|c|c|c|c|}
\hline \multirow[t]{3}{*}{ Tratamentos } & \multicolumn{6}{|c|}{ Médias } \\
\hline & $\mathrm{CR}$ & $\mathrm{PE}$ & TME & IVE & MSPA* & $\mathrm{MSR}^{*}$ \\
\hline & $(\mathrm{cm})$ & $(\%)$ & (dias) & & (g) & \\
\hline 1 - Solo & $6,77 \mathrm{a}$ & $53,3 \mathrm{a}$ & $6,21 \mathrm{a}$ & $0,13 \mathrm{a}$ & $0,42 \mathrm{a}$ & $0,35 \mathrm{a}$ \\
\hline 2 - (3) solo + (1) composto & $6,77 \mathrm{a}$ & $61,6 \mathrm{a}$ & $5,10 \mathrm{a}$ & $0,16 \mathrm{a}$ & $0,44 \mathrm{a}$ & $0,34 \mathrm{a}$ \\
\hline 3 - (3) solo + (2) composto & $7,20 \mathrm{a}$ & $58,3 \mathrm{a}$ & $5,20 \mathrm{a}$ & $0,17 \mathrm{ab}$ & $0,38 \mathrm{a}$ & $0,32 \mathrm{a}$ \\
\hline 4 - Solo + composto & $7,21 \mathrm{a}$ & $76,6 \mathrm{~b}$ & $4,50 \mathrm{a}$ & $0,21 \mathrm{~b}$ & $0,49 \mathrm{a}$ & $0,37 \mathrm{a}$ \\
\hline 5 - Composto & $6,77 \mathrm{a}$ & $65,8 \mathrm{ab}$ & $4,83 \mathrm{a}$ & $0,16 \mathrm{a}$ & $0,41 \mathrm{a}$ & $0,35 \mathrm{a}$ \\
\hline CV (\%) & 5,21 & 12,86 & 22,63 & 12,86 & 16,56 & 16,12 \\
\hline
\end{tabular}

Médias seguidas de mesma letra, na coluna, não diferem entre si pelo teste de Tukey a 5\% de probabilidade. *Médias de dados transformados pela razão de $(\mathrm{x})^{\wedge} 0,5$.

Nas avaliações ficou ressalvado que proporções iguais de solo e composto (Tratamento 4) ajudam no ganho de massa e no desenvolvimento das mudas indicando o potencial nutricional do material orgânico na composição do substrato e a sua boa relação com solo o qual ofereceu características físicas positivas ao mesmo. Araújo Neto et al. (2009), destacam que as mudas de pimentão cultivadas com uma mistura de composto orgânico, coprólitos e casca de arroz carbonizada foram as que apresentaram os melhores resultados para as características massa seca de raiz e total.

Houve diferença estatística para as variáveis índice de velocidade de emergência e porcentagem de emergência onde o tratamento 4 continuou apresentando melhores médias. O IVE apresentou o valor de 0,21 dias no tratamento em questão e a PE 76,6\% (Tabela 5), confirmando ainda mais que quantidades iguais de composto e solo são adequadas para tal cultura nas condições do local do experimento.

Em trabalho realizado por Santos et al. (2010), quando avaliaram o efeito de vermicomposto na produção de pimentão, ressaltaram que os tratamentos com 100\% desse composto orgânico diminuíram o percentual de emergência e o IVE, destacam que isso pode-se atribuir ao fato da baixa aeração exercida por esse substrato às mudas.

$\mathrm{O}$ composto à base de resíduos de pequi proporcionou o desenvolvimento das plântulas dessa cultura, provavelmente, em função do seu conteúdo de nutrientes. Esses resultados corroboram com outros estudos que apontam efeitos positivos do uso de resíduos urbanos e industriais no aumento da fitomassa de plantas (ARAÚJO et al., 2007).

Os substratos utilizados no experimento proporcionaram resultados satisfatórios ficando entre bom e fácil a muito bom e ótimo para as variáveis: facilidade de retirada da planta da célula (FR), agregação do substrato às raízes (AS) aparentadas nas Tabelas 6 e 7.
Tabela 6. Características do composto a base de resíduos de pequi, facilidade de retirada da planta da célula (FR), agregação do substrato às raízes (AS) e necrose da radícula (N) para a cultura do tomate.

\begin{tabular}{cccc}
\hline Tratamentos & FR & AS & N \\
\hline 1 & 3 & 2 & $\mathrm{~N}$ \\
2 & 3 & 2 & $\mathrm{~N}$ \\
3 & 3 & 2 & $\mathrm{~N}$ \\
4 & 3 & 2 & $\mathrm{~N}$ \\
5 & 3 & 2 & $\mathrm{~N}$ \\
\hline
\end{tabular}

*Para facilidade de retirada da planta da célula e agregação do substrato às raízes atribuíram-se notas: 1 (difícil ou ruim), 2 (fácil ou boa) e 3 (muito fácil ou ótima), respectivamente. *Para necrose na radícula atribui-se n (ausência) e s (presença).

Tabela 7. Características do composto a base de resíduos de pequi, facilidade de retirada da planta da célula (FR), agregação do substrato às raízes (AS) e necrose da radícula (N) para a cultura do pimentão.

\begin{tabular}{cccc}
\hline Tratamentos & FR & AS & N \\
\hline 1 & 3 & 2 & $\mathrm{~N}$ \\
2 & 3 & 2 & $\mathrm{~N}$ \\
3 & 3 & 2 & $\mathrm{~N}$ \\
4 & 3 & 2 & $\mathrm{~N}$ \\
5 & 3 & 2 & $\mathrm{~N}$ \\
\hline
\end{tabular}

* Para facilidade de retirada da planta da célula e agregação do substrato às raízes atribuíram-se notas: 1 (difícil ou ruim), 2 (fácil ou boa) e 3 (muito fácil ou ótima), respectivamente. *Para necrose na radícula atribui-se $\mathrm{n}$ (ausência) e s (presença).

O enraizamento mais homogêneo é de grande importância, conforme trabalho de Silva et al. (2011), relatando que quanto maior a homogeneidade e volume de raízes, maior será a quantidade de nutrientes disponíveis no intervalo entre o transplantio e a formação de novas raízes. Além disso, Filgueira (2008) afirmou que um bom enraizamento favorece o reinício do desenvolvimento da planta, após o choque do processo de transplantio. Dessa forma, com o uso do substrato à base de composto há possibilidade de se produzir mudas mais adequadas para o transplantio, 
proporcionando maior capacidade de pegamento em condições de campo.

As mudas de tomate e pimentão não apresentaram necrose da radícula, demonstrando manejo apropriado e substrato com boas condições fitossanitárias para produção de mudas sadias.

\section{Conclusões}

O composto obtido a partir das cascas do pequi mostrou potencial para adubo orgânico na formação de substratos agrícolas quando misturado com a mesma proporção de solo, promovendo mudas de pimentão e de tomate de elevada qualidade.

Para as mudas de tomateiro a mistura de composto e solo em proporções iguais se mostrou favorável apenas à emergência, contudo para o pimentão formou as melhores mudas.

Com relação as variáveis ligadas ao substrato todos os substratos avaliados obtiveram nota muito fácil para facilidade de retirada da plântula da célula e boa agregação do substrato às raízes e nenhuma raiz com necrose.

\section{Referências Bibliográficas}

ARAÚJO NETO, S. E. DE; AZEVEDO, J. M. A. DE; GALVÃO, R. O.; OLIVEIRA, E. B. L.; FERREIRA, R. L. F. Produção de muda orgânica de pimentão com diferentes substratos. Ciência Rural, Santa Maria-RS, v. 39, n. 5, p. 1408-1413, 2009.

ARAÚJO, A. S. F.; MONTEIRO, R. T. R.; CARVALHO, E. M. S. Effect of composted textile sludge on growth, nodulation and nitrogen fixation of soybean and cowpea. Bioresource Technology, New York-US, v. 97, n. 1, p. 10281032, 2007.

BORCHARTT, L.; SILVA, I. F.; SANTANA, E. O.; SOUZA, C.; FERREIRA, L. E. Adubação orgânica da batata com esterco bovino no município de Esperança - PB. Revista Ciência Agronômica, Fortaleza-CE, v. 42, n. 2, p. 482-487, 2011.

CAMPANHARO, M.; RODRIGUES, J. J. V.; JUNIOR, M. A. L.; ESPINDULA, M. C.; COSTA, J. V. T. Características físicas de diferentes substratos para produção de mudas de tomateiro. Revista Caatinga, Mossoró-RN, v. 19, n. 2, p. 40145, 2006.

CARVALHO, J. L.; PAGLIUCA, L. G. Tomate: Um mercado que não para de crescer globalmente. Revista Hortifruti Brasil, Piracicaba-SP, v. 58, n. 1, p. 6-14, 2007.

CORREIA, D.; ROSA, M. F.; NOROES, E. R. V. Uso do pó da casca de coco na formulação de substratos para formação de mudas enxertadas de cajueiro anão precoce. Revista Brasileira de Fruticultura, Jaboticabal-SP, v. 25, n. 3, p.5 57-558, 2003
COSTA, C. A.; RAMOS, S. J.; SAMPAIO, R. A.; GUILHERME, D. O.; FERNANDES, L. A. Fibra de coco e resíduo de algodão para substrato de mudas de tomateiro. Horticultura Brasileira, Brasília-DF, v. 25, n. 3, p. 387-391, 2007.

COSTA, E.; DURANTE, L. G. Y.; NAGEL, P. L.; FERREIRA, C. R.; SANTOS, A. Qualidade de mudas de berinjela submetida a diferentes métodos de produção. Revista Ciência Agronômica, Fortaleza-CE, v. 42, n. 4, p. 1017-1025, 2011.

COSTA, E.; JORGE, M. H. A.; SCHWERZ, F.; CORTELASSI, J. A. S. Emergência e fitomassa de mudas de pimentão em diferentes substratos. Revista Agrária, RecifePE, v. 8, p. 396-401, 2013.

COSTA, L. A. M.; COSTA, M. S. S. M.; PEREIRA, D. C.; BERNARDI, F. H.; MACCARI, S. Avaliação de substratos para a produção de mudas de tomate e pepino. Revista Ceres, Viçosa-MG, v. 60, n. 5, p. 675-682, 2013.

CURI, N.; KÄMPF, N.; MARQUES, J. J. Mineralogia e formas de potássio em solos do Brasil. In: YAMADA, T.; ROBERTS, T. L., eds. Potássio na agricultura brasileira. Piracicaba-SP: Associação Brasileira para a Pesquisa da Potassa e do Fosfato, 2005. p.71-92.

DINIZ, K. A.; GUIMARÃES, S. T. M. R.; LUZ, J. M. Q. Húmus como substrato para a produção de mudas de tomate, pimentão e alface. Bioscience Journal, Uberlândia-MG, v. 22, n. 3, p. 63-70, 2006.

DOMÍNGUEZ, J.; LAZCANO, C.; GÓMEZ-BRANDÓN, M. Influencia del vermicompost en el crecimiento de las plantas. Aportes para la elaboración de um concepto objetivo. Acta Zoológica Mexicana, Cidade do México, v. 2, edição especial, p. 359-371, 2010.

FERREIRA, D. F. SISVAR: a computer statistical analysis system. Ciência e Agrotecnologia, Lavras-MG, v. 35, n. 6, p. 1039-1042, 2011.

FILGUEIRA, F. A. R. Novo manual de olericultura: agrotecnologia moderna na produção e comercialização de hortaliças. 3. ed. Viçosa-MG: Editora UFV, 2008. 412 p.

HENZ, G. P.; COSTA, C. S. R.; CARVALHO, S.; BANCI, C. A. Como cultivar pimentão: alta produtividade. Cultivar hortaliças e frutas, Pelotas-RS, v. 7, n. 1, p. 1-6, 2007.

IPECE. INSTITUTO DE PESQUISA E ESTRATÉGIA ECONÔMICA DO CEARÁ. Ceará em mapas. 2007. Disponível em:<

http://www2.ipece.ce.gov.br/atlas/capitulo1/12/124x.htm>. Acesso em: 25 out. 2014.

LOPES, A. S.; GUILHERME, L. R. G. Interpretação de análise de solo: conceitos e aplicações. 3. ed. São Paulo-SP: Associação Nacional Para a Difusão de Adubos (ANDA), 1992. 64 p. (Boletim Técnico, 2).

MAGUIRE, J. D. Speed of germination-aid in selection and evaluation for seedling emergence and vigor. Crop Science, Madison-US, v. 2, n. 1, p.1 76-177, 1962

MARFÁ, O.; GURI, S. Física de substratos y oxigenación del medio radicular. In: FERNANDÉZ, M. F.; GÓMEZ, I. M. C. 
ed. Cultivos sin suelo II. Almeria: DGIFA/FIAPA/Caja Rural de Almeria, 1999, p. 93-106.

OLIVEIRA, M. E. B.; GUERRA, N. B.; MAIA, A. H. N.; ALVES, R. E.; XAVIER, D. S.; MATOS, N. M. S. Caracterização física de frutos do pequizeiro nativos da chapada do Araripe-CE. Revista Brasileira de Fruticultura, Jaboticabal-SP, v. 31, n. 4, p. 1196-1201, 2009.

PEREIRA, W. E.; SOUSA, G. G.; ALENCAR, M. L.; MENDONÇA, R. M. N.; SILVA, G. L. Crescimento de mudas de mamoeiro em substratos contendo caulim. Revista Verde de Agroecologia e Desenvolvimento Sustentável, Mossoró-RN, v.3, n.1, p 27-35, 2008.

RIBEIRO, A. C.; GUIMARAES, P. T. G.; ALVAREZ, V. V. $H$. Recomendações para o uso de corretivos e fertilizantes em Minas Gerais. $5^{\text {a }}$ Aproximação. Viçosa-MG: Comissão de Fertilidade do Solo do Estado de Minas Gerais, 1999. 359p.

RODRIGUES, E. T.; LEAL, P. A. M.; COSTA, E.; PAULA, T. S.; GOMES, V. A. Produção de mudas de tomateiro em diferentes substratos e recipientes em ambiente protegido. Horticultura Brasileira, Brasília-DF, v. 28, n. 4, p. 483-488, 2010.

SANTANA, C. T. C.; SANTI, A.; DALLACORT, R.; SANTOS, M. L.; MENEZES, C. B. Desempenho de cultivares de alface americana em resposta a diferentes doses de torta de filtro. Revista Ciência Agronômica, Fortaleza-CE, v. 43, n. 1, p. 22-29, 2012.

SANTOS, D. C.; FERREIRA, R. L. F.; ARAÚJO NETO, S. E.; QUEIROZ, E. F.; MEDEIROS, R. S. Produção de mudas de tomateiro em substratos alternativos. Enciclopédia Biosfera, Goiânia-GO, v. 11, n. 21, p. 1530-1541, 2015.
SANTOS, M. R.; SEDIYAMA, M. A. N.; SALGADO, L. T.; VIDIGAL, S. M.; REIGADO, F. R. Produção de mudas de pimentão em substratos à base de vermicomposto. Bioscience Journal, Uberlândia-MG, v. 26, n. 4, p. 572-578, 2010.

SCHERER, E. E. Níveis críticos de potássio para soja em Latossolo húmico de Santa Catarina. Revista Brasileira de Ciência do Solo, Viçosa-MG, v. 22, n. 1, p. 57-62, 1998.

SILVA, J. B. C.; NAKAGAWA, J. Estudos de fórmulas para cálculo da velocidade de germinação. Informativo ABRATES, Londrina-PR, v. 5, n. 1, p. 62-73, 1995.

SILVA, J. D. C.; LEAL, T. T. B.; ARAÚJO, R. M.; GOMES, R. L. F.; ARAÚJO, A. S. F.; MELO, W.J. Emergência e crescimento inicial de plântulas de pimenta ornamental e celosia em substrato à base de composto de lodo de curtume. Revista Ciência Rural, Santa Maria-RS, v. 41, n. 3, p. 412417, 2011

SOUSA, D. M. G.; LOBATO, E. (Ed.). Cerrado: correção do solo e adubação. 2. ed. Brasília-DF: Embrapa Informação Tecnológica, 2004. 416 p.

TEDESCO, M. J.; GIANELLO, C.; ANGHINONI, I.; BISSANI, C. A.; CAMARGO, F. A. O.; WIETHÖLTER, S. (Ed.). Manual de adubação e calagem para os estados do Rio Grande do Sul e de Santa Catarina. 10. ed. Porto Alegre-RS: SBCS-NRS, 2004. 400p. 